Plant Tissue Cult. \& Biotech. 30(2): 277-283, 2020 (December)

(C)Bangladesh Assoc. for Plant Tissue Culture \& Biotechnology

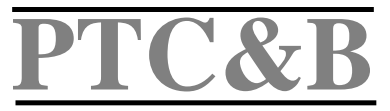

\title{
In vitro Regeneration of Wedelia calendulacea Less. - A Valuable Endangered Medicinal Plant
}

\author{
Sabina Yesmin* \\ Plant Biotechnology Division, National Institute of Biotechnology, Ganakbari, Savar, \\ Dhaka-1349, Bangladesh
}

Key words: Wedelia calendulacea, Nodal segments, Shoot tips, Regeneration

\begin{abstract}
Direct plant regeneration from shoot tips and nodal explants of Wedelia calendulacea Less. was carried out in MS with different concentrations and combinations of BAP, $\mathrm{Kn}$ and NAA. Of the two explants nodal segments showed the best response towards the formation of multiple shoots in MS containing BAP (2.0 mg $/)$, $\mathrm{Kn}(1.0 \mathrm{mg} /)$ and NAA $(0.5 \mathrm{mg} /)$. In this combination, the maximum number of shoots/explant obtained was $18.33 \pm 0.72$ from shoot tips and $26.64 \pm 0.47$ from nodal explants. Cent per cent root formation was obtained in MS with IBA $(0.2 \mathrm{mg} \Lambda)$ within three weeks. The in vitro regenerated plantlets were successfully transplanted to soil for further growth and development.
\end{abstract}

\section{Introduction}

Wedelia calendulacea Less. is a creepy, perennial herb with camphor-like odor belongs to Asteraceae (Sharmin et al. 2014). It is a traditional Ayurvedic herbal medicinal plant and grows plentifully in the tropical and sub-tropical regions of the world (Baki et al. 2002). In Bangladesh it is commonly known as "Mohabhringaraj". Wedelia calendulacea is a profusely branched tree with fleshy leaves spreading like a carpet making a dense cover. The tree blooms abundantly with yellow flowers. This plant is commonly grown by the road sides and national highways.

Wedelia calendulacea Less., is widely used in Ayurvedic practices, modern pharmaceutical industries and local preparations for liver diseasess, snake bites, skin disease and septic shock and in several other diseases like hepatic and splenic enlargement (Kobori et al. 2004, Pocas et al. 2006). The alcoholic extract of leaves, roots and areal parts of $W$. calendulacea are reported to show the defensive activity against liver damage and stimulates liver secretory capacity (Varsha et al. 2011).

*Author for correspondence: <sabinanib79@gmail.com>.

DOI: https://doi.org/10.3329/ptcb.v30i2.50697 
In recent years, most of the pharmaceutical and Ayurvedic industries harvest medicinal plants on a large scale from their natural habitats and thereby reduce its local population. The seeds of Wedelia sp. show very low span of viability and is inadequate for the preservation of the seed materials for commercial cultivation (Martin et al. 2003). A few reports on the in vitro regeneration of Wedelia calendulacea are available (Lisa et al. 2014 and Sharmin et al. 2014). Considering the importance of this valuable plant species for its use in drug attempt was made for the development of rapid and efficient in vitro method for propagation of Wedelia calendulacea.

\section{Materials and Methods}

This study was conducted in the Plant Biotechnology Division of National Institute of Biotechnology of Bangladesh. Plant material of Wedelia calendulacea Less. was collected from the medicinal plant garden of National Institute of Biotechnology campus. The nodal segments and shoot tips were used as explants. For in vitro organogenesis, nodal segments $(1.5-2.0 \mathrm{~cm})$ and shoot tips $(2.0-4.0 \mathrm{~mm})$ were excised from naturally grown plants. Both the explants were surface sterilized (Yesmin 2019) using $0.3 \%$ antifungal bavistin for $10 \mathrm{~min}$ and $0.1 \%$ aqueous solution $(\mathrm{w} / \mathrm{v})$ of $\mathrm{HgCl}_{2}$ for four $\mathrm{min}$. Then the explants were cultured on MS containing 3\% sucrose and BAP and $\mathrm{Kn}(1.0-5.0 \mathrm{mg} /)$ singly or in combination with NAA $(0.5-1.0 \mathrm{mg} /)$. The $\mathrm{pH}$ was adjusted 5.8 before autoclaving. After inoculation, all the cultures were maintained at $25 \pm 2^{\circ} \mathrm{C}$ and $16 / 8 \mathrm{hrs}$ (light/dark) photoperiod. After two - three weeks the explants were sub-cultured at a regular interval of 10 - 15 days.

For root induction, $3-4 \mathrm{~cm}$ long shoots were separated and transferred to half and full-strength MS with (0.2 - $0.5 \mathrm{mg} /$ ) IBA, IAA and NAA alone. The plantlets with well developed roots were transferred in small plastic pots containing autoclaved soil. In order to keep a high moisture, the pots were then covered with transparent polythene bags and acclimatized in the growth room condition $\left(25 \pm 2^{\circ} \mathrm{C}\right)$ for $2-3$ weeks. Finally, these hardened plantlets were transferred to the natural condition for their further growth and development.

\section{Results and Discussion}

There are a lot of reports in which shoot tips and nodal segments were used as explants in other medicinal and economically important plants (Biswas et at. 2009, Binita et al. 2005, Kalimuthu et al. 2007, Hassan and Roy 2004, Sultana and Handique 2004, Jain et al. 2003 and Chandramu et al. 2003). Between the two explants, nodal segment was found to be the most responsive in terms of percentage of shoot regeneration as well as the number of shoots per explant (Table 1). Shoot tips and nodal segments were cultured on MS with different concentrations of BAP (1.0 - $5.0 \mathrm{mg} \Lambda)$ and $\mathrm{Kn}(1.0$ - $5.0 \mathrm{mg} \Lambda)$ singly and with different concentrations of NAA $(0.5-1.0 \mathrm{mg} \Lambda)$ for multiple shoot formation. In case of BAP, the best result was obtained in MS with BAP $(3.0 \mathrm{mg} \Lambda)$ from both the explants. In 
this concentration, initiation of shoot started within 8 - 10 days. Highest percentage (80 and 87) of response showed in both the explants for shoot induction. The maximum mean number $(5.00 \pm 0.29$ and $6.20 \pm 0.55)$ of shoots/explant and the average mean length $(1.02 \pm 0.07$ and $1.37 \pm 0.10 \mathrm{~cm})$ of shoots were recorded in this concentration by both the explants. Rahman and Bhadra (2011) stated that medium containing BAP (3.0 mg/) showed best response for shoot formation (7.0 \pm 0.29 shoots/explant) from nodal explants of $W$. chinensis (Osbeek) Merr. But they reported best response ( $3.5 \pm 0.33)$ shoots/explants from shoot tip explants on MS with BAP $(2.0 \mathrm{mg} /)$. On the other hand, in $\mathrm{Kn}$ the shoot tip explants showed highest percentage (73) of response, maximum number $(3.80 \pm 0.73)$ of shoots/explant with an average length of shoots $(1.06 \pm 0.10 \mathrm{~cm})$ in MS with $\mathrm{Kn}(2.0$ $\mathrm{mg}$ /). Nodal explants showed highest percentage (67) of response and maximum number $(4.60 \pm 0.76)$ of shoots/explant with an average length of shoots $(1.23 \pm 0.11 \mathrm{~cm})$ in MS with Kn (3.0 mg 1$)$ (Table 1).

Table 1. Effects of BAP, Kn and NAA on multiple shoot regeneration from shoot tips and nodal segments of Wedelia calendulacea.

\begin{tabular}{|c|c|c|c|c|c|c|c|c|}
\hline \multicolumn{3}{|c|}{$\begin{array}{c}\text { Growth } \\
\text { regulators }(\mathrm{mg} /)\end{array}$} & \multicolumn{3}{|c|}{$\begin{array}{l}\text { Shoot } \\
\text { tips }\end{array}$} & \multicolumn{3}{|c|}{$\begin{array}{c}\text { Nodal } \\
\text { segments }\end{array}$} \\
\hline BAP & Kn & NAA & $\begin{array}{l}\% \text { of } \\
\text { responsive } \\
\text { explants }\end{array}$ & $\begin{array}{c}\text { Mean no. of } \\
\text { shoots/explant } \\
\quad( \pm \text { SE })\end{array}$ & $\begin{array}{c}\text { Mean length } \\
\text { of shoots } \\
(\mathrm{cm}) \pm S E\end{array}$ & $\begin{array}{l}\text { \% of } \\
\text { responsive } \\
\text { explants }\end{array}$ & $\begin{array}{c}\text { Mean no. of } \\
\text { shoots/ } \\
\text { explant }( \pm S E)\end{array}$ & $\begin{array}{c}\text { Mean length } \\
\text { of shoots } \\
(\mathrm{cm}) \pm \mathrm{SE}\end{array}$ \\
\hline 1.0 & - & - & 53 & $2.27 \pm 0.45$ & $0.74 \pm 0.06$ & 60 & $3.36 \pm 0.62$ & $1.08 \pm 0.08$ \\
\hline 2.0 & - & - & 67 & $3.53 \pm 0.42$ & $0.95 \pm 0.06$ & 73 & $4.46 \pm 0.42$ & $1.22 \pm 0.10$ \\
\hline 3.0 & - & - & 87 & $5.00 \pm 0.29$ & $1.02 \pm 0.07$ & 80 & $6.20 \pm 0.55$ & $1.37 \pm 0.10$ \\
\hline 4.0 & - & - & 73 & $3.60 \pm 0.64$ & $0.65 \pm 0.05$ & 67 & $3.53 \pm 0.72$ & $0.88 \pm 0.05$ \\
\hline \multirow[t]{6}{*}{5.0} & - & - & 47 & $1.73 \pm 0.54$ & $0.62 \pm 0.05$ & 60 & $2.06 \pm 0.51$ & $0.71 \pm 0.04$ \\
\hline & 1.0 & - & 47 & $2.00 \pm 0.60$ & $0.8 \pm 0.04$ & 53 & $2.60 \pm 0.68$ & $0.96 \pm 0.08$ \\
\hline & 2.0 & - & 73 & $3.80 \pm 0.73$ & $1.06 \pm 0.10$ & 67 & $4.00 \pm 0.80$ & $1.07 \pm 0.07$ \\
\hline & 3.0 & - & 53 & $2.80 \pm 0.73$ & $0.96 \pm 0.06$ & 80 & $4.60 \pm 0.76$ & $1.23 \pm 0.11$ \\
\hline & 4.0 & - & 53 & $2.73 \pm 0.51$ & $0.89 \pm 0.08$ & 60 & $2.78 \pm 0.52$ & $0.97 \pm 0.09$ \\
\hline & 5.0 & - & 40 & $1.53 \pm 0.51$ & $0.86 \pm 0.07$ & 47 & $2.06 \pm 0.53$ & $0.92 \pm 0.07$ \\
\hline 2.0 & 1.0 & - & 80 & $10.47 \pm 1.40$ & $1.52 \pm 0.12$ & 93 & $13.21 \pm 0.65$ & $1.87 \pm 0.09$ \\
\hline 3.0 & 1.0 & - & 73 & $5.14 \pm 0.93$ & $0.78 \pm 0.08$ & 80 & $7.64 \pm 1.43$ & $1.07 \pm 0.09$ \\
\hline 4.0 & 1.0 & - & 60 & $4.00 \pm 0.96$ & $0.76 \pm 0.05$ & 67 & $3.33 \pm 0.68$ & $0.89 \pm 0.07$ \\
\hline 2.0 & 1.0 & 0.5 & 93 & $18.33 \pm 0.72$ & $1.8 \pm 0.11$ & 100 & $26.64 \pm 0.47$ & $2.13 \pm 0.14$ \\
\hline 2.0 & 1.0 & 1.0 & 73 & $4.21 \pm 0.71$ & $0.8 \pm 0.06$ & 67 & $5.14 \pm 0.64$ & $1.15 \pm 0.16$ \\
\hline 3.0 & 1.0 & 0.5 & 80 & $4.46 \pm 0.73$ & $1.04 \pm 0.10$ & 80 & $4.00 \pm 0.48$ & $1.55 \pm 0.18$ \\
\hline 3.0 & 1.0 & 1.0 & 67 & $2.33 \pm 0.55$ & $0.85 \pm 0.05$ & 60 & $3.06 \pm 0.62$ & $0.99 \pm 0.12$ \\
\hline
\end{tabular}

The combined effect of BAP and Kn in MS was tested to see their effect on direct multiple shoot regeneration from both the explants. When shoot tips and nodal segments were cultured on MS with BAP $(2.0 \mathrm{mg} /)$ and $\mathrm{Kn}(1.0 \mathrm{mg} \Lambda)$ a considerable number of 
explants responded to regeneration. The highest number of explants $(80 \%$ in shoot tips and $93 \%$ in nodal segments) were found to response for regeneration in this combination. Initiation of shoot started within one week after inoculation of both the explants (Figs $1 \mathrm{a}, \mathrm{b})$. In this combination the mean number of shoots from shoot tip explant were $10.47 \pm$ 1.40 shoot/explant with their average length $1.52 \pm 0.12 \mathrm{~cm}$. The mean of number shoots
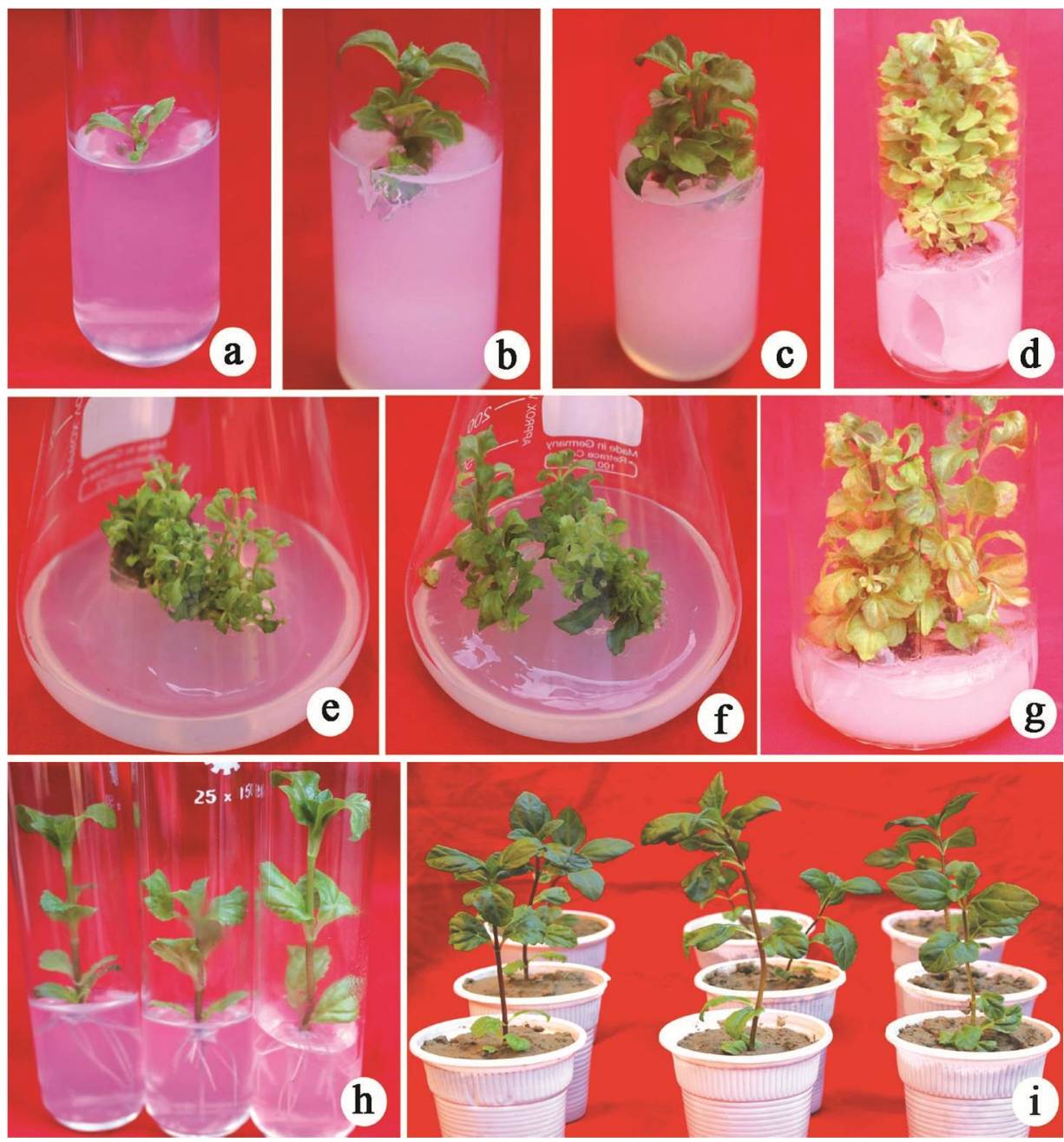

Fig. 1. Shoot proliferation of Wedelia calendulacea from shoot tip and nodal segments. (a) Induction of shoots from shoot tips explants on MS +3.0 mg/ BAP, (b) initiation of multiple shoots from nodal segments on MS $+2.0 \mathrm{mg} / \mathrm{BAP}+1.0 \mathrm{mg} / \mathrm{Kn}$, (c) initiation of multiple shoots from nodal explants on $\mathrm{MS}+2.0 \mathrm{mg} / \mathrm{BAP}+$ $1.0 \mathrm{mg} / \mathrm{Kn}+0.5 \mathrm{mg} / \mathrm{NAA}$, (d) development of small shoots from nodal explants in the same regeneration medium after four weeks of culture, (e) multiplication of shoots from shoot tips explants in the same regeneration medium, (f) same as Fig. e but in case of nodal explants, (g) elongation and proliferation of in vitro shoots on MS basal medium, (h) rooting of in vitro regenerated shoots on MS $+0.2 \mathrm{mg} / \mathrm{IBA}$, (i) Transplantation of regenerated plantlets in small plastic pots containing sterilized soil. 
from nodal explants were $13.21 \pm 0.65$ shoots/explant with their average length $1.87 \pm 0.09$ $\mathrm{cm}$ (Table 1). Martin et al. (2003) showed the combined effect of BA $(8.87 \mu \mathrm{M})$ and $\mathrm{Kn}$ $(2.32 \mu \mathrm{M})$ for the induction of multiple shoots from nodal explants in $W$. chinensis (Osbeek) Merr., Lisa et al. (2014) reported that MS with BAP (0.5 mg/1) and Kn (1.5 $\mathrm{mg} / 1)$ proved superior for shoot initiation from nodal explants of $W$. calendulacea. A lower concentration of Kn and NAA and a slightly higher concentration of BAP produced best results in shoot formation. The percentage of response of explants, number of shoots/explants, length of shoots and their proliferation varied with the constituent of the medium. In the present study, among the four different media used the shoot tip and nodal explants in MS with BAP $(2.0 \mathrm{mg} \Lambda), \mathrm{Kn}(1.0 \mathrm{mg} \Lambda)$ and NAA $(0.5 \mathrm{mg} \Lambda)$ grew vigorously and started producing multiple shoots within 5 to 7 days (Fig. 1c). The highest percentage of responsive explants (93 and 100) were observed in MS + BAP (2.0 $\mathrm{mg} \Lambda)+\mathrm{Kn}(1.0 \mathrm{mg} \Lambda)+\mathrm{NAA}(0.5 \mathrm{mg} /)$. The maximum number $(18.33 \pm 0.72$ and $26.64 \pm$ $0.47)$ of shoots per explants and shoot length $(1.8 \pm 0.11$ and $2.13 \pm 0.14 \mathrm{~cm})$ were found in this medium in both explants, respectively. Fig. 1d shows the formation of small shoots

Table 2. Effects of growth regulators on in vitro root induction in regenerated shoots of Wedelia calendulacea on half and full-strength of MS.

\begin{tabular}{lccccccc}
\hline $\begin{array}{l}\text { MS } \\
\text { strength }\end{array}$ & IBA & IAA & NAA & $\begin{array}{c}\text { Rooted } \\
\text { shoots }(\%)\end{array}$ & $\begin{array}{c}\text { Initiation of } \\
\text { roots (days) }\end{array}$ & $\begin{array}{c}\text { Mean no. of roots/ } \\
\text { shoot }( \pm \text { SE) }\end{array}$ & $\begin{array}{c}\text { Mean length of } \\
\text { roots }(\mathrm{cm})( \pm \text { SE })\end{array}$ \\
\hline $1 / 2$ MS & - & - & & 50 & $12-14$ & $2.60 \pm 0.22$ & $3.52 \pm 0.16$ \\
$1 / 2$ MS & 0.2 & & & 70 & $12-13$ & $4.10 \pm 0.38$ & $3.98 \pm 0.16$ \\
$1 / 2$ MS & 0.5 & & & 55 & $13-14$ & $3.50 \pm 0.45$ & $4.41 \pm 0.23$ \\
$1 / 2$ MS & & 0.2 & & 45 & $11-12$ & $2.50 \pm 0.22$ & $3.91 \pm 0.26$ \\
$1 / 2$ MS & & 0.5 & & 40 & $12-13$ & $2.90 \pm 0.38$ & $3.65 \pm 0.17$ \\
$1 / 2$ MS & & & 0.2 & 40 & $11-12$ & $3.50 \pm 0.40$ & $3.89 \pm 0.18$ \\
$1 / 2$ MS & & & 0.5 & 35 & $12-13$ & $2.50 \pm 0.17$ & $3.51 \pm 0.20$ \\
MS & - & - & - & 60 & $10-11$ & $5.30 \pm 0.52$ & $4.10 \pm 0.34$ \\
MS & $\mathbf{0 . 2}$ & & & $\mathbf{1 0 0}$ & $\mathbf{7 - 8}$ & $\mathbf{9 . 4 0} \pm \mathbf{0 . 6 9}$ & $\mathbf{5 . 6 0} \pm \mathbf{0 . 3 2}$ \\
MS & 0.5 & & & 70 & $10-12$ & $4.20 \pm 0.33$ & $4.01 \pm 0.17$ \\
MS & & $\mathbf{0 . 2}$ & & $\mathbf{7 5}$ & $\mathbf{1 0 - 1 1}$ & $\mathbf{4 . 7 0} \pm \mathbf{0 . 4 2}$ & $\mathbf{4 . 3 5} \pm \mathbf{0 . 3 1}$ \\
MS & & 0.5 & & 50 & $12-13$ & $4.00 \pm 0.33$ & $3.91 \pm 0.21$ \\
MS & & & 0.2 & 50 & $12-14$ & $4.10 \pm 0.43$ & $4.23 \pm 0.25$ \\
MS & & & 0.5 & 40 & $13-15$ & $2.90 \pm 0.46$ & $3.51 \pm 0.17$ \\
\hline
\end{tabular}

regenerated from nodal explants after four weeks. The in vitro regenerated shoots were cut into pieces with a single node and subcultured in the same regeneration medium for further multiplication. Rahman and Bhadra (2011) also reported that MS with BAP (2.0 $\mathrm{mg} \Lambda)$ and NAA $(0.5 \mathrm{mg} \Lambda$ ) was most effective for shoot induction in W. chinensis (Osbeek) Merr. In the present study it was observed that explants with small shoots subcultured in the same medium produced increased number of multiple shoots but the shoot length 
was found to decrease. Repeated subcultures in the same medium at 8 - 10 days intervals resulted increased number of shoots (Figs 1e,f). For shoot elongation and proliferation, the regenerated small multiple shoots were transferred to MS without PGRs (Fig. 1g). These shoots were maintained in the same medium for further their multiplication.

Individual elongated shoots ( $3-4 \mathrm{~cm}$ long) were excised from shoot clumps and transferred to root induction medium. For rooting half and full strength of MS with different concentrations (0.1 - $1.00 \mathrm{mg} /)$ of IBA, IAA and NAA were used (Table 2). The efficient root formation and growth was obtained in full strength MS with IBA $(0.2 \mathrm{mg} /)$. Initiation of roots was observed within seven days and sufficiently developed roots were found after three weeks of inoculation. The maximum percentage (100) of development of roots, maximum number of roots $(9.40 \pm 0.69)$ and their highest length $(5.60 \pm 0.32 \mathrm{~cm})$ were recorded in full strength MS with IBA $(0.2 \mathrm{mg} \Lambda)$ (Fig. 1h). Earlier reports (Lisa et al. 2014, Rahman and Bhadra 2011) stated root formation in Wedelia by using high concentrations of IBA in half strength MS or MS. Agarwala et al. (2010) reported autorooting in Wedelia chinensis on MS with BAP (1.5 mg 1$)$ + GA3 (0.5 g/). Martin et al. (2003) also reported ex vitro rooting in Wedelia chinensis.

After sufficient development of roots the in vitro regenerated plantlets were successfully transplanted into small plastic pots containing sterilized soil (Fig. 1i). After two to three weeks of transplantation when the plantlets completely acclimatized in soil they were transferred to large earthen pots for further growth and development. In here, $97 \%$ of transplanted plantlets survived. On the basis of the above discussion it may be concluded that the in vitro regeneration protocol developed in the present study can be successfully exploited for large scale clonal propagation and conservation of this valuable and endangered medicinal plant species.

\section{References}

Agarwala B, Azam FMS, Khatun MA, Rahman F and Rahmatullah (2010) Simultaneous shoot regeneration and rhizogenesis of Wedelia chinensis for in vitro clonal propagation. AmericanEurasian J. Sustainable Agriculture 4(1): 65-69.

Baki MA, Rahman MAA, Khatune NA, Zahid RA, Khalequzzaman, Husain MM and Sadik G (2002) Synergic effects of Wedelia calendulacea Less. plant extracts with Lamda cyhalothrin on common housefly Musca domestica L. Biological Sciences 2(10): 686-689.

Binita BC, Ashok MD and Yogesh TJ (2005) Bacopa monnieri (L.) Pennell: A rapid, efficient and cost effective micropropagation. Plant Tissue Cult. \& Biotech. 15(2): 167-147.

Biswas A, Bari MA, Roy M and Bhadra SK (2009) Clonal propagation through nodal explant culture of Boerhaavia diffusa L.-A rare medicinal plant. Plant tissue cult. \& Biotech. 19(1): 53-59.

Chandramu C, Rao DM and Reddy VD (2003) High frequency induction of multiple shoots from nodal explants of Vitex negundu L. using sodium sulphate. J. Plant Biotechnol. 5(2): 107-113.

Hassan AKMS and Roy SK (2004) Micropropagation of Smilex zeylanica L., a perennial climbing medicinal shrub, through axillary shoot proliferation. Bangladesh J. Life Sci. 6(1): 33-39. 
Jain V, Singh D and Saraf S (2003) In vitro micropropagation of Rauwolfia serpemtina through multiple shoot generation. Ancient Science of life 23(1): 44-49.

Kalimuthu K, Paulsamy S, Senthilkumar R and Sathya M (2007) In vitro propagation of the biodiesel plant Jatropha curcus L. Plant Tissue Cult. \& Biotech. 17(2): 137-175.

Kobori M, Yang Z, Gong D, Heissmeyer V, Zhu H, Jung YK, Gakidis MA, Rao A, Sekine T, Ikegami F, Yuan C and Yuan J (2004) Wedelolactone suppress LPS-induced caspase11 expression by directly inhibiting the IKK complex. Cell Death and Differentiation 11: 123-130.

Lisa SF, Lithy SS, Rashid HO, Mahdi R, Azam FMS and Rahmatullah M (2014) In vitro mass propagation of Wedelia calendulacea Less., a rare medicinal herb. Am. Eurasian J. Sus. Agri. 8(5): 18-25.

Martin KP, Beena MR and Joseph D (2003) high frequency axillary bud multiplication and ex vitro rooting of Wedelia Chinensis (Osbeck) Merr. - a medicinal plant. Indian J. Exp. Bio. 41: 262-266.

Pocas ESC, Lopes DVS, da Silva AJM, Pimenta PHC, Leitao FB, Netto CD, Buarque CD, Brito FV, Costa PRR and Noel F (2006) Structure-activity relationship of wedelolactone analogues: Structural requirements for inhibition of $\mathrm{Na}+\mathrm{K}+\mathrm{ATPase}$ and binding to the central benzodiazepine receptor. Bioorganic and Medicinal Chemistry, 14: 7962-7966.

Rahman MM and Bhadra SK (2011) Development of protocol for in vitro culture and rapid propagation of Wedelia chinensis (Osbeek) Merr. J. of Medicinal Plants Res. 5(11): 2387-2392.

Sabina Yesmin (2019) In Vitro Micropropagation of Stevia rebaudiana Bertoni. Plant Tissue Cult. \& Biotech. 29(2): 277-284.

Sharmin SA, Alam MJ, Md. Sheikh MMI, Sarker KK, Khalekuzzaman M, Haque MA, Alam MF and Alam I (2014) Somatic embryogenesis and plant regeneration in Wedelia calendulacea Less. an endangered medicinal plant. Brazilian Archives of Biology and Technology 57(3): 394-401.

Sultana S and Handique PJ (2004) Micropropagation of Wedelia chinensis through high frequency shoot multiplication using nodal explants. J. Curr. Sci. 5: 447-452.

Varsha K, Nema AK and Agarwal A (2011) Hepatoprotective prospective of herbal drugs and their vesicular carriers-A review. IJPBR. 2: 360-374. 